\title{
ESTUDO SOBRE AVALIAÇÃO DE DESEMMPENHO DE ENFERMEIRAS. METODOLOGIA UTILIZADA E RESULTADOS \\ ENCONTRADOS - PARTE II
}

Paulina Kurcgant*

KURCGANT, P. Estudo sobre avaliação de desempenho de enfermeiras: metodologia utilizada e resultados encontrados - Parte II. Rev. Esc. Enf. USP, São Paulo, $20(2): 143-160,1986$.

Nesta segunda parte do estudo sobre avaliação do desempenho de enfermeiras é apresentada a metodologia adotada, os instrumentos utilizados para a coleta de dados $e$ os critérios adotados na discussão dos resultados. É apresentada, também, parte da discussão dos resultados, o que obedecem, para melhor compreensão, a uma seqüência pré-determinada. Dessa forma são discutidos resultados referentes aos itens "objetivos dos programas de avaliação de desempenho" e "elementos responsáveis pela avaliação de desempenho". Este último item subdivide-se em "caracterização profissional", que $\dot{e}$ totalmente discutida nesta parte do estudo, e "preparo profissional especifico", que será apresentado na terceira parte do trabalho. O referencial teórico pertinerte a resultados faz parte da discussão aqui apresentada.

Para melhor compreensão da problemática, que envolve a avaliação de desempenho das enfermeiras em nosso meio, foi realizado um estudo junto às profissionais que exercem atividades técnico-específicas em hospitais gerais do município de São Paulo.

\section{MATERIAL E MÉTODO}

Como população do estudo foram considerados, inicialmente, os 65 hospitais gerais em funcionamento, com mais de 100 leitos, localizados no município de São Paulo

Em seguida investigou-se, nesses hospitais, a existência, ou não, de um programa de avaliação de desempenho com registro em impresso específico.

Os 65 hospitais foram analisados, ainda, quanto à entidade mantenedora, número de enfermeiras, número de leitos e proporção de enfermeiras-leitos.

Dos 65 hospitais analisados, 22 utilizavam algum impresso na avaliação das enfermeiras. Verificou-se que nos hospitais que não utilizavarn impresso, a relação era de uma enfermeira para 24 leitos, e nos que uti. lizavam registro, a relação era de uma enfermeira para 8 leitos.

Os 22 hospitais que utilizavam impresso e que passaram a ser o universo do estudo apresentavam a seguinte distribuição de enfermeiras: $i$

- Enfermeira. Professor Assistente Doutor do Departamento de Orientação Profissional da Escola de Enfermagem da USP - disciplina Administracão Aplicada a Cinfermagem. 
hospitais governamentais contavam com 465 profissionais; 7 hospitais particulares lucrativos contavam com 108; e 8 hospitais particulares não lucrativos contavam com 305 enfermeiras.

Para proceder ao processo da amostragem e com o objetivo de sc manter a representatividade das enfermeiras, segundo a entidade man tenedora desses hospitais, optou-se por uma amostragem estratificada pur partilha proporcional.

Como estratos foram considerados os três tipos de entidades mantc. nedoras e, dentro de cada estrato, entrevistaram-se $10 \%$ das respectivas enfermeiras. Foram sorteados os hospitais que, segundo a entidade man tenedora, seriam visitados seqüencialmente, até serem atingidos os $10 \%$ do número de profissionais necessários para a amostra de cada estrato.

Para a seleção das enfermeiras utilizou-se, em cada instituição, o se guinte critério: eram selecionadas as profissionais que constavam da escala mensal das enfermeiras no dia da visita à instituição, independente do turno de trabalho (manhã, tarde ou noite); caso não fossem atin gidos os $10 \%$ necessários para a amostra do estrato naquela instituição, partia-se para a instituição seguinte de acordo com a seqüencia do sorteio.

Dessa forma, foram entrevistadas 89 enfermeiras, sendo 47 em três hospitais governamentais assim distribuidas: 20 enfermeiras no primeiro hospital, 17 no segundo e 10 no terceiro. Quanto aos hospitais lucrativos foram entrevistadas 11 enfermeiras num único hospital. Nos hospitais não lucrativos foram entrevistadas 24 enfermeiras no primeiro hospital e 7 no segundo, num total de 31 .

\section{Procedimento}

A coleta de dados foi realizadas no periodo compreendido entre janeiro de 1982 e fevereiro de 1983.

Após o entrosamento inicial com as instituições e obtenção do consentimento para a realização da pesquisa, foi marcada a data para a entrevista com a Chefe do Serviço de Enfermagem. Nessa ocasião foram expostos os objetivos do estudo, mostrados os instrumentos de coleta de dados e solicitada cópia do impresso de avaliação de desempenho de enfermeiras utilizado na instituição.

$O$ impresso de avaliação foi entregue em data oportuna e as entre vistas, após a definição da amostra do estudo, foram marcadas com as enfermeiras de acordo com a disponibilidade de cada uma.

As entrevistas realizadas com as Chefes dos Serviços de Enfermagem e com as Enfermeiras Avaliadoras e Avaliadas obedeceram aos seguintes critérios de seleção: 1 . foram selecionadas, dentre as enfermeiras do hospital em estudo, aquelas que participaram do processo avaliatórıo como avaliadora e como avaliada desde o $2 .^{\circ}$ semestre de $1981 ; 2$. as Enfermeiras Avaliadoras e Avaliadas que exerciam atividades de enfermagem em unidades de internação, em centro cirúrgico e em unidades de 
terapia intensiva; 3. foram selecionadas, rigorosamente, somente a En. fermeira Avaliadora e sua(s) respectiva(s) Enfermeira(s) avaliada(s); 4. as Enfermeiras Avaliadoras e Avaliadas foram entrevistadas independentemente do cargo que ocupavam na instituição; 5. Quando a Chefe do Serviço de Enfermagem era também Enfermeira Avaliadora, foram feitas duas entrevistas com a mesma pessoa, sendo ela entrevistada uma vez como Chefe do Serviço e outra como Avaliadora; o espaço mínimo de tempo entre as duas entrevistadas foi sempre de um mês.

\section{Instrumento de coleta de dados}

Pela própria caracterização do assunto em estudo achou-se por bem utilizar formulários para a coleta de dados. Dessa forma elaborados três instrumentos, tendo um sido aplicado à Chefe do Serviço de Enfermagem outro às Enfermeiras Avaliadoras e um terceiro às Enfermeiras Avalia das (Anexos I, II e III).

Antes da aplicação dos formulários, estes foram submetidos a prèteste, depois do que foram modificados, novamente testados e, finalmente, aprovados como instrumentos para a coleta de dados do estudo.

\section{Critérios para análise das respostas}

Antes da análise das respostas dos formulários foram estabelecidos critérios que nortearam o procedimento.

Para a análise das respostas dos formulários (Anexos II eIII) referentes ao conteúdo dos instrumentos de avaliação, foram estabelecidos critérios que classificaram os prognosticadores dos instrumentos utilizados em pessoais e profissionais.

Foram considerados como prognosticadores pessoais as caracteristicas inatas e as aprendidas durante a vida do individuo e que lhe conferem algo de próprio e particular como ser humano.

Foram ainda considerados prognosticadores pessoais quando, na análise desses prognosticadores, foram utilizados parâmetros estabelecidos pela sociedade visando o homem no convivio social.

Como prognosticadores profissionais foram consideradas as características passiveis de serem assimiladas pelos indivíduos por processo de ensino-aprendizagem, dirigidas para o desenvolvimento de determinadas atividades e relativas a determinada profissão.

Foram ainda considerados prognosticadores profissionais quando, na análise desses prognosticadores, foram utilizados parâmetros estabele cidos pela organização visando o homem e a produção.

Para a análise das respostas à mesma questão fechada contida nos formulários 1, 2 e 3, foi considerada resposta coincidente (C) quando foram assinalados, nos diferentes formulários, exatamente o(s) mesmo(s) iten(s) da questão, e não coincidente (NC) quando isto não ocorreu. 
Para a análise das respostas ảs questoes abertas dos formulários 2 e 3 referentes aos significados dos prognosticadores, foram estabelecidos critérios que classificaram as respostas em coincidentes (C), não coincidentes (NC) e parcialmente coincidentes (PC).

Foram consideradas respostas coincidentes (C) quando, na interpretação do significado do prognosticador, a Enfermeira Avaliadora e respectiva Enfermeira Avaliada utilizaram as mesmas palavras-chaves:

- quando todas as idéias contidas em ambas as respostas foram semelhantes.

Foram consideradas respostas não coincidentes (NC) quando, na interpretação do significado do prognosticador, a Enfermeira Avaliadora e respectiva Enfermeira Avaliada não utilizaram uma única pala vra-chave comum a ambas as respostas:

- quando nenhuma idéia registrada foi semelhante em ambas as respostas.

Foram consideradas respostas parcialmente coincidentes (PC), quando a interpretação do significado do prognosticador, feita pela Enfermeira Avaliadora e respectiva Enfermeira Avaliada, incluiu o conteúdo da resposta da Enfermeira Avaliadora ou Avaliada, independentemente dessc conteúdo estar acrescido de outros significados:

- quando, mesmo utilizando palavras diferentes, parte do conteúdo mantinha o mesmo significado;

- quando foram utilizadas uma ou mais palavras-chaves (não todas) comuns a ambas as respostas.

Para análise das respostas dos formulários 2 e 3 referentes aos sentimentos que envolvem a avaliação, foi utilizada a escala de TRIANDIS ${ }^{25}$, que consiste em graduar o sentimento em cinco níveis. $1^{\circ}$ nivel corres. ponde à existência plena de um sentimento e o $5^{\circ}$ nivel corresponde à existência plena de um sentimento oposto ao do $1^{\circ}$ nível. $\mathrm{O} 3^{\circ}$ nivel cor responde à indiferença quanto ao sentimento estudado e os niveis $2^{\circ}$ e $4^{4}$ são graduados entre os anteriores.

\section{Análise e discussão dos resultados}

A análise e discussão dos resultados obedeceram a uma seqüência prédeterminada do assunto avaliação de desempenho, com a finalidade de facilitar a compreensão do estudo. De acordo com essa seqüência são analisados os dados referentes aos «objetivos dos programas de avaliação de desempenho», «elementos responsáveis pela avaliação»; "preparo dos elementos que participam do processo de avaliação» que, por sua vez, se subdivide em dois ítens: «caracterização profissional» e "preparo profis sional especifico»; «freqüência das avaliações»; «técnicas utilizadas no processo de avaliação»; «métodos utilizados na avaliação de enfermeiras»; «instrumentos de avaliação de desempenho» e «sentimentos que envoi.vem a avaliação». 
Foram também estabelecidas as seguintes abreviações que visamı facilitar a apresentação da análise: hospitais governamentais (H.G.); hospitais lucrativos (H.L.); hospitais não lucrativos (H.N.L.); chefe do Ser. viço de Enfermagem (chefe do S.E.); enfermeira avaliadora (enf. Ar); enfermeira chefe (C); avaliadora (Ar) e avaliada (Av).

Os resultados referentes aos objetivos da avaliação de desempenho demonstram como as chefes do S.E. e respectivas enfermeiras $\operatorname{Ar}(\mathrm{s})$ a enfermeiras Av(s) consideram o uso da avaliação de desempenho no hospital onde trabalham.

Esses resultados mostram que existe consenso nas respostas assina ladas pelas chefes do S.E., enfermeira $\operatorname{Ar}(s)$ e enfermeiras $\operatorname{Av}(s)$ dos H.G. e H.L. pois todas consideram coincidentemente a «admissão, demissão e promoção do pessoal» como o objetivo primeiro do uso da avaliaçấ: de desempenho nesses hospitais. Como segundo objetivo, por elas assinalado, encontramos «subsidiar programas de desenvolvimento de pessoal» e como terceiro objetivo encontramos «mudanças de procedimentos em enfermagem».

Mostram também que as enfermeiras chefes do S.E., enfermeira Ar(s) e enfermeira Av(s) dos H.N.L. consideram coincidentemente o uso maior da avaliação de desempenho na «admissão, demissão e promoção de pes soal» seguido da utilização da avaliação como subsídio para «programdis de desenvolvimento de pessoal de enfermagem». Essas enfermeiras não consideram como objetivo da avaliação nos hospitais onde trabalham «mudanças de procedimentos em enfermagem».

Os percentuais mais altos de coincidência, ou seja, maior concor dância nas respostas encontram-se entre as enfermeiras que trabalham no H.L. seguido das enfermeiras que trabalham nos H.G. e por último as enfermeiras dos H.N.L.

Apenas uma das enfermeiras Av(s) de um H.N.L. assinalou o iter: «outras formas», informando que no hospital onde trabalhava a avaliação de desempenho é utilizada para «estimular o próprio funcionário».

Quando as mesmas enfermeiras chefes do S.E., enfermeiras $\operatorname{Ar}(s)$ e enfermeiras $\mathrm{Av}(\mathrm{s})$ dos H.G., H.L. e H.N.L. foram questionadas quanto a «por que» consideravam a avaliação importante, sugeriram outros objetivos que, segundo elas, deveriam ser os dois programas de avaliação.

Assim, foram encontrados os seguintes objetivos da avaliação de desempenho: para o avaliado corrigir falhas de desempenho, para promover o pessoal, para o avaliado saber como está sendo considerado para motivar o pessoal, para o indivíduo produzir, para a organização conhecer seu pessoal, como oportunidade para esclarecer dúvidas, para melhorar o relacionamento entre a avaliadora e a avaliada e para o crescimento do avaliado como pessoa.

Verificou-se, ainda, que nos H.G. as 46 enfermeiras respondentes consideraram, principalmente, a avaliação importante "para o avaliado corrigir falhas». No H.L. as 11 enfermeiras consideraram como prioridade 
do uso da avaliação, «saber como o avaliado está sendo considerado, e, nos H.N.L., as 31 enfermeiras consideraram, como o uso mais importante da avaliação, «o desenvolvimento do pessoal».

Verificou-se, portanto, que segundo as enfermeiras, nas organizações onde trabalham, o objetivo principal da avaliação é a «admissão demissão e transferência» de pessoal. Quando, se expressam livremente sobre qual deveria ser o uso principal da avaliação, foram encontrados os seguintes pontos: "para o avaliado corrigir falhas», para «saber como está sendo considerado e para «desenvolvimento do pessoal» o que eviden cia, claramente, que as enfermeiras consideram a «avaliação de desem penho» importante para o aprimoramento do próprio desempenho. Verifica-se, portanto, que os objetivos das organizações diferem dos objetivos das enfermeiras.

Muitos dos pontos levantados pelas enfermeiras do estudo também o são por administradores.

Segundo CHIAVENATO9, a avaliação de desempenho serve para adequar o indivíduo ao cargo; para o treinamento do pessoal; para dirigir promoções; como incentivo salarial; como melhoria das relações humanas entre superior e subordinado; como auto-aperfeiçoamentc do empregado; para informações básicas na pesquisa de recursos humanos; para estimativa do potencial dos funcionários; como estímulo para maiol' produtividade; para conhecer o desempenho da empresa; como retroali. mentação ao próprio indivíduo avaliado e outras decisões de pessoal, como transferências e demissões.

GRILLO 14, analisando o uso da avaliação de desempenho na admi. nistração pública, verificou que a visão que esse serviço tem da avaliação é unilateral, uma vez que a utiliza na promoção de funcionários ou aumento de salários. Segundo ele, essa visão é inadequada, porque : avaliação é o meio de se obterem informações a respeito das pessoas qui trabalham e sem essas informações será difícil implementar um progra ma de recursos humanos.

BERGAMINI ${ }^{5}$, é de decisão que a avaliação de desempenho contribui para o Desenvolvimento Oganizacional (D.O), porque ajuda o avaliado a decidir por esta ou aquela estratégia comportamental, uma vez que é por meio da avaliação que o indivíduo toma consciência de seli po. tencial e o transforma em ponto de desenvolvimento.

Para AQUINO ${ }^{2}$, PATZ ${ }^{22}$ e JUCIUS ${ }^{16}$, o objetivo básico da avaliaçâo é o de coletar informações sobre dois aspectos básicos do funcionário do hospital: os resultados do seu trabalho no desempenho de um cargo e $u$ seu potencial; consideram que essas inforfomações são úteis para efeitos de decisões administrativas e para planejamento do desenvolvimento do funcionário.

E ainda BERGAMINI ${ }^{6}$, que considera o uso da avaliação para puniı irresponsáveis ou para aumentar lucros, como objetivos que devem ser afastados. Segundo ela, a avaliação em si mesma não tem o poder de 
atingir objetivo algum, a não ser o de facilitar o diagnóstico dos fatores que estejam dificultando ou impedindo a utilização dos insumos humanos dentro das organizaçōes. São as medidas administrativas ou o uso da avaliação que darão o verdadeiro sentido de sua utilidade.

Para SOUTH ${ }^{23}$ o objetivo primeiro do uso da avaliação de enfermeiras é o contínuo desenvolvimento do pessoal de enfermagem.

Para COCHRAN \& HANSEN 10 os propósitos de um sistema de ava liação de enfermeiras são: aprimoramento ou manutenção da eficiência do pessoal; conscientização, por parte das enfermeiras, de quais fatores constituem um desempenho eficiente e atendimento a requisitos admsnistrativos.

Quanto à participação de diferentes elementos no processo avaliativo, verificou-se que, para o estabelecimento dos atuais sistemas de avaliação de enfermeiras, os H.G. não tiveram a participação da chefe do S.E. e os H.L. e H.N.L. não tiveram a participação das enfermeiras do hospital. A participação da administração do hospital foi evidenciada em todos os hospitais e a participação de elementos estranhos ao hospital só foi assinalada. nos H.G.

Verificou-se também que nos H.G. a administração do hospital participa do planejamento, implantação e execução da avaliação; no H.L. participa somente na execução e nos H.N.L. a administração não interfere na avaliação das enfermeiras.

Os resultados do estudo nesse item mostram uma contraāição, pois, segundo uma das chefes do S.E. dos H.N.L., existe a participação efetiva da administração do hospital no estabelecimento do atual sistema de avaliação e, segundo ela mesma, quando inquerida em «como a adminis tração participa», respondeu que «a administração não interfere na avaliação das enfermeiras».

BERGAMINI ${ }^{7}$ diz que, a rigor, nenhum programa de avaliação de desempenho deveria ser levado a efeito sem o conhecimento dos estilos comportamentais das pessoas que compõem o quadro da organização, pois considera, por exemplo, que os componentes da área financeira se conduzem de forma diferente dos que trabalham na linha de produção.

Considerou-se que a não participação da chefe do S.E. ou das enfermeiras do hospital no estabelecimento do sistema de avaliação das enfermeiras dificulta a caracterização do estilo comportamental dessas profissionais e, conseqüentemente, a determinação de um programa de ava iação adequada.

Outro aspecto também discutido por BERGAMINI 4 é que, para o estabelecimento de um sistema de avaliação, é importante que se conheça «como se produz o produto ou o serviço a ser oferecido, sua tecnologia e seu ritmo de produtividade».

A não participação das enfermeiras nesse processo, não permite c conhecimento da tecnologia de enfermagem e do rítimo necessário ao de- 
senvolvimento dessa tecnologia e, portanto, não subsidia a avaliação das enfermeiras com parâmetros adequados de desempenho.

BERGAMINI ${ }^{4}$ considera, ainda, que a participação da cúpula da organização é indispensável e, caso contrário, estar-se-á dispendendo muito esforço para a obtenção de resultados duvidosos. A participação da administração do hospital no processo de avaliação é importante porque facilita a implantação do sistema, que segue, via de regra, o sentido cúpula-base.

Para CHIAVENATO ${ }^{9}$, em algumas organizações existe uma rígiđa centralização da responsabilidade pela avaliação no orgão de «staff» da área de Recursos Humanos; em outras, há a decentralização, sendo a responsabilidade fixada no avaliado, e alguma responsabilidade no chele imediato. Considera, ainda, que o meio termo, mais utilizado, consiste ni centralização, no que tange ao projeto, à construção e à implantação do sistema e na relativa descentralização, no que tange à aplicação e execução.

Quanto à participação dos diferentes elementos na elaboração do: instrumentos de avaliação utilizados verificou-se que existe, em todos os hospitais, a participação das chefes do S.E. ou das enfermeiras. A ad ministração do hospital não participa da elaboração do instrumento no: H.N.L., segundo as chefes do S.E.

Analisando esse aspecto BERGAMINI 6 mostra que dois elementos devem ser considerados na elaboração do instrumento de avaliação: as características do trabalho em si e as possiveis variações comportamentais que poderão ser exibidas ao executá-lo.

Considerou-se de grande importância a participação da chefe do S.E. e das enfermeiras dos hospitais na elaboração do instrumento de avaliação, por serem os elementos capazes de selecionarem tanto as características do trabalho como as do trabalho como a do profissional que executa esse trabalho.

Quanto ao fato de se conhecer quem avalia as enfermeiras, verificou-se que a administração do hospital não participa do processo em qualquer dos hospitais do estudo. Foi verificada a participação dos chefes imediatos, do chefe imediato, da própria enfermeira (auto-avaliação) e da enfermeira da «educação em serviço» na avaliação direta das enfermeiras. Como forma indireta verificou-se a participação da chefe do S.E. e de uma comissão de avaliação na revisão da avaliação já feita pelo chefe imediato.

Verificou-se, ainda, que a participação de um único avaliador como elemento determinante da avaliação também ocorre nos hospitais do estudo.

A participação de subordinados, de outras enfermeiras e de outros profissionais na avaliação das enfermeiras não acontece nos hospitais estudados. 
Segundo CHERNUSFIN \& GALVIN 8, para se conseguir uma avaliação de enfermeiras a mais isenta possível de preconceitos deve-se promover a participação da enfermeira avaliadora, da enfermeira avaliada e do médico da equipe, a fim de ser atingido consenso sobre a enfermeira que está sendo avaliada.

KOONTZ ${ }^{19}$ considera que a eficácia da avaliação pode ser aumentada com a participação do chefe do avaliador na avaliação de um subordinado. O chefe do avaliador poderá participar, juntamente com o avaliador da avaliação que está sendo feita, ou fazer a revisão da avaliação já realizada.

YODER ${ }^{26}$ considera que a avaliação pelo supervisor direto ocorre em $75 \%$ da prática; em $10 \%$ é feita por uma comissão de avaliação e as demais formas ocorrem em proporções menores.

DAU ${ }^{11}, \mathrm{KABOT}^{17}$, DUNN ${ }^{12}$, e $\mathrm{ADAMII}^{1}$ evvidenciam a importância da participação de mais de um avaliador no processo de avaliação das enfermeiras.

MOORE \& SIMENDINGER 20 consideram salutar quando os subordinados avaliam seus chefes e HAMRIC et alii ${ }^{15}$ aprovam o fato de um colega avaliar o outro.

BERGAMINI 4, CHIAVENATO ${ }^{9}$, ARGYRIS ${ }^{3}$, OLIVEIRA ${ }^{21}$, SUND \& PICAR ${ }^{24}$, KENNEDY ${ }^{18}$ consideram adequado quando o avaliado julga seu próprio desempenho.

Foi verificado, também, que nos H.G. e H.N.L. a participação dos avaliadores ocorre nas fases de planejamento, implantação e execução do processo de avaliação. No H.L. verificou-se, que na fase de execução do processo, o avaliador emite julgamento sem antes discutir a avaliação com o avaliado. Nos H.G. e H.L. o avaliado não participa da elaboração do impresso de avaliação. Verificou-se, também, que dos 35 avaliados dos H.G., dos 9 avaliados do H.L. e dos 27 dos H.N.L., respectivamente 6,3 e 5 informaram não ter qualquer participação além de serem avaliados pelos respectivos avaliadores.

PATZ ${ }^{22}$, após pesquisar como era feita a avaliação de desempenho em 19 organizações industriais, verificou-se as diferenças existentes na participação do avaliador e do avaliado. Verificou que, em alguns casos, era realizada a entrevista formal de avaliação entre o avaliador e o avaliado; em outros; o avaliado era informado do julgamento feito pelo seu supervisor imediato e em outros, ainda, os resultados da avaliação eram mantidos em segredo; verificou, também, que a participação do pessoal no sistema adotado contribuia decisivamente para ressaltar os aspectos positivos, tanto políticos como interpessoais, da avaliação de desempenho. Segundo PATZ 22 todo avaliador deve solicitar o ponto de vista de seu avaliado antes de chegar à conclusão da avaliação.

Para BERGAMINI 5, a maioria dos programas de avaliação nas empresas considera o avaliador como um elemento passivo que «conhece» 0 avaliado e «preenche» a ficha de avaliação de forma adequada. 
YODER ${ }^{26}$ verificou-se que em $1 / 3$ das empresas em que foi analisado o processo da avaliação, os avaliadores discutem a avaliação com os subordinados; considera, também, que, se o superior discute as ações dos subordinados quando elas ocorrem, pouco tem a acrescentar na entrevista de avaliação.

FLIPPO ${ }^{13}$ considera que a mensuração tradicional pede ao avaliador que «faça o papel de Deus» e que profira sentenças sobre seres humanos; por esse motivo preconiza uma forma de avaliação que envolva um grau muito alto de participação do subordinado.

KABOT ${ }^{17}$ diz que, além da chefe do S.E., há necessidade das enfermeiras avaliadoras discutirem o processo de avaliação, porque só dessa maneira poderão entender os objetivos e conteúdo dos instrumentos utilizados, bem como, se envolverem diretamente na determinação do nivel de assistência de enfermagem que esperam de seu pessoal.

Para que a avaliação produza os efeitos desejáveis, ADAMI $^{1}$ considera imprescindivel que o supervisor informe seus subordinados dos resultados da avaliação por meio da entrevista.

Para CHIAVENATO ${ }^{9}$ a comunicação do resultado da avaliação ao subordinado é ponto fundamental de quase todas as sistemáticas de avaliação de desempenho; de nada adianta a avaliação se o maior interessado, o próprio avaliado, não tomar conhecimento dela.

KURCGANT, P. Study on nurse performance evaluation: used methodology and obtained results - Part II. Rev. Esc. Enf. USP, São Paulo, 20(2):143-160, 1986.

In this second part of this study the methodology, the instruments utilized for the data gathering and the criteria used in the discussion of the date are presented. Part of the discussion of the results, which, for better comprehension, follow $a$ pre-established path, is also presented. The results concerning the itens "objectives of the performance evaluation programs" and "elements responsible for the performance evaluation" are discussed. This last item is subdivided into "profissional characterization", which is totally discussed in this part of the study, and "specific professional skill" which will be presented in the third part of this paper. The theoretical background related to the results is contained in the discussion presented.

\section{REFERENCIAS BIBLIOGRAFICAS}

1. ADAMI, N.P. Avaliaçăo de desempenho do pessoal de enfermagem de saúde pública: aplicação a situações de superviẵo. Enf. Novas Dimens., São Paulo, 3(5):267-82, set./out. 1977.

2. AQUINO, C.P. Avalíặăo de desempenho. Rev. Paul. Hosp., São Paulo, 27(9):284-91, set. 1979.

3. ARGYRIS, C. A integragio individuo-organizacão. Săo Paulo, Atlas, 1975. p. 1-290.

4. BERGamini, C.W. Avaliacão de desempenho humano na empresa. 3. ed. São Paulo, Atlas, 1977. 274p.

5. 126-32.

Desenvolvimento de recursos humanos. Săo Paulo, Atlas, 1980. p.11-63,

6. Novo exame preocupado da avaliação de desempenho. Rev. Adm., São Paulo, 18(2):5-11, abr./jun. 1983. 
7. Por que falham os sistemas de avaliação de desempenho? Săo Paulo, Fundação Getúlio Vargas, 1979. p.1-27.

8. CHERNUShIN, N. \& GALVIN, J.H. Evaluation that is Prankly subjective. Amer. J. Nurs., New York, 62(2):92-3, Feb. 1962.

9. ChIAVenato, I. Administração de recursos humanos. 2. ed., São Paulo, Atlas, 1980. v.2. 341p.

10. COCHRAN, T.C. \& HANSEN, P.J. Desarrollo de um instrumento de evaluación mediante la acción de grupo. Washington, Organización Panamericana de la Salud, 1963. p. 87-97. (Publicacion Clentifica, 78).

11. DAU, G. The appraisal process. Superv. Nurse, Chicago, 7(8):39-42, Aug. 1976.

12. DUNN, M.A. Development of an instrument to measure nursing performance. Nurs. Res., New York, 19(6):502-10, Nov./Dec. 1970.

13. FLIPPO, E.B. Princípios de administração de pessoal. São Paulo, Atlas, 1976. p.287-305.

14. GRILlo, A.N. Avaliação de desempenho: a experiência brastleira na administração pública. Rev. Adm., São Paulo, 17(1):24-38, jan./mar. 1982.

15. HAMRIC, A.B.; GRESHAM, L.; ECCARD, M. Staff evaluation of clinical leaders. J. Nurs. Adm., Wakefield, 8(1):18-26, Jan. 1978.

16. JUCIUS, M. Administração de pessoal. São Paulo, Saraiva, 1979. p.368-87.

17. КАВОт, L.B. Objective evaluation for clinical performance. Superv. Nurse, Chicago, 8(11): 16-8, Nov. 1977.

18. KENNEDY, J.A. The meaning of evaluation. Nurs. Outlook, New York, 9(7):438-40, July, 1961.

19. KoONTZ, H. Avaliacão de objetivos. Rio de Janeiro, Livros técnicos e clentificos, 1974. $196 \mathrm{p}$.

20. MOORE, T.F. \& SIMENDINGER, E. Evaluation as a two-way street. Superv. Nurse, Chicago, $7(6): 58-9$, Jun. 1976.

21. Oliveira, M.A. Análise e solucão de problemas de desempenho na empresa. Săo Paulo, Atlas, 1977. p.11-28.

22. PATZ, A.L. Avaliação do desempenho: útil mas ainda combatida. Expansão, são Paulo, $4(90)$ : $41-51$, ago. 1975 .

23. SOUTH, J.C. The performance profile: a technique for using appraisals effectively. J. Nurs. Adm., Wakefield, 8(1):27-31, Jan. 1978.

24. SUND, R.B. \& PICARD, A.J. Objetivos comportamentais e medidas de avaliação: clências e matomática. São Paulo, EPU, 1978. p.9-127.

25. TRIANDIS, H.C. Attitudes and attitude change. New York, Wihey, 1971.

26. YODER, D. Administraç̃o de pessoal e relacões industriais. Săo Paulo, Mestre Jou, 1969. v.2. p.428-52. 


\section{ANEXO I \\ FORMULARIO 1 - CHFFE DO SERVICO DE ENFERMAGEM}

1 - Quem estabeleceu o atual sistema de avaliação de enfermeiras:

- a administração do hospital ( )

- a chefe do S.E. ( )

- enfermeiras do hospital ( )

- elementos não pertencentes ao hospital ( )

- outros ( )

2 - Quem elaborou o atual impresso de avaliação:

- a administração do haspital ( )

- a chefe do S.E. ( )

- enfermeiras do hospital ( )

- elementos não pertencentes ao hospital ( )

- outros ( )

3 - Na avaliação de desempenho em enfermagem quem avalia as enfermeiras das unidades:

- a administração do haspital ( )

- os chefes imediatos ( )

- o chefe imediato ( )

- a própria enfermeira (auto - avaliação) ( )

- outras

4 - Como elemento integrante do processo de avaliação no hospital, o avaliador: - recebe orientação verbal - sistematizada (obedece programação) ( ) - não sistematizada (esclarecimento de dúvidas) ( )

- recebe orientação escrita - sitematizada (manual de avaliador) ( )

- outras ( )

5 - Quem faz a arientação dos avaliadores:

- a administraçãa do hospital ( )

- a chefe do S.E. ( )

- outros serviços do hospital ( )

- colegas de serviço ( )

- outros ( )

6 - No caso do hospital dar orientação ao avaliador, qual a frequência dessa orientação:

- quando o avaliador solicita ( )

- quandio a administração considera necessária ( )

- existe programação pré-estabelecida para essa orientação ( )

- outras formas ( )

7 - A administração do haspital procede na avaliação:

- determinando o processo de avaliação ( ) 
- estabelecendo o impresso de avaliação ( )

- discutindo o preenchimento do impresso com o avaliador ( )

- não interfere na avaliação ( )

- outras formas $($ )

8 - Qual a freqüência da avaliação de enfermeiras nas unidades de internação:

- mensal ( )

- trimestral ( )

- semestral ( )

- anual ( )

- outras ( )

9 - O Serviço de Enfermagem utiliza as resultados da avaliação como subsídios para:

- promoção do pessoal ( )

- programas de desenvolvimento de pessaal ( )

- mudanças de procedimentos ( )

- outros ( )

10 - A quem se destina o impresso de avaliação:

- só para enfermeiras ( )

- para a equipe de enfermagem ( )

- para todos as funcionários ( )

- s6 para funcionários universitários ( )

- outros ( )

11 - Qual a importancia da avaliação.

\section{ANEXX II \\ FORMULARIO 2 - AVALIADOR}

1 - Há quanto tempo exerce a profissão?
- 1 a 2 anos ( )
- 4 a 8 anos ()
- 2 a 4 anos ( )
- 8 a 16 anos ( )
- mais de 16 anos ( )

2 - Fez outros cursos após o graduação:

- atualização (cursos de curta duraçãa) ( )

- especialização (carga horária mínima de 240h) ( )

- pós-graduação (mestrado e doutoramento) ( )

3 - Há quanto tempo exerce a profissão em cargo de chefia:
- 1 més a 1 ano ( )
- 1 a 2 anos ( )
- 4 a 8 anos ()
- 2 a 4 anos $(\quad)$
- 8 a 16 anos ( )
- mais de 16 anos ( )

4 - Qual o numero de vezes que você teve oportunidade de avaliar enfermeiras:
- $1-5()$
- $6-10()$
$-41-80(\quad)$
- $11-20(\quad)$
$-81-160()$
$-21-40()$ 
5 - No conteúdo programático dos cursas que realizou como estava inserido o assunto avaliação de desempenho:

- o assunto não foi abordado ( )

- abordagem teorica ( )

- abordagem prática ( )

- abordagem teórica-prática ( )

- outras formas

6 - Quem faz a orientação dos avaliadiores:

- a administração do hospital ( )

- a chefe do S.E. ( )

- outros serviços do haspital ( )

- colegas de serviço ( )

- outros ( )

7 - Como é feita a orientação a avaliador sobre o processo de availação:

- não recebe orientação especifica ( )

- recebe orientação verbal - sistematizada (obedece programação) ( )

- não sistematizada (esclarecimento de dúvidas) ( )

- recebe orientação escrita - sistematizada (manual do avaliadior) ( )

- outras ( )

8 - No caso do hospital dar orientação ao avaliador, qual a frequência dessa orientação:

- quando o avaliador solicita ( )

- quando a administração considera necessária ( )

- existe programação pré-estabelecida para essa orientação ( )

- outras formas ( )

9 - Que técnicas você utiliza para obter informações sobre a avaliado:

- observação sistematizada e esporádica ( )

- observação não sistematizada e contínua ( )

- observação não sistematizada e esporédica ( )

- entrevistas ( )

- comunicação verbal ( )

- comunicação escrita (relatórios) ( )

- reunióes ( )

- outras formas ( )

10 - Como você se sente como avaliador:

- totalmente segura ( )

- segura ( )

- com alguma insegurança ( )

- insegura ( )

- totalmente insegura ( ) 
11 - Assinale as sentimentos que prevalet:em em você após a avaliação:

- justiça (1)

- lealdade (1)

- honestidade (1)

- correção (1)

- confiança (1)

- alegria (1)

- imparcialidade

- integridade (1)

- verdade (1)

-- convicção

- apreço (1)

- calma (1)

- benefício (1)

- prazer (1)

- outras (1) \begin{tabular}{lllllll}
1 & 2 & 3 & 4 & 5 & 5 & - \\
\hline
\end{tabular}

\begin{tabular}{llllll}
1 & 2 & 3 & 4 & 5 & 5 \\
\hline & 1 & 1 & 1 & 1
\end{tabular}

$\begin{array}{llllll}1 & 2 & 3 & 4 & 5\end{array}-$ desonestidade (5)

— incorreção (5)

- desconfiança (5)

- tristeza (5)

- parcialidade (5)

- corrupção (5)

- inverdade (5)

- dúvida (5)

$\begin{array}{lllll}1 & 2 & 3 & 4 & 5 \\ 1 & 1 & 1 & 1 & 1 \\ 1 & 2 & 3 & 4 & 5 \\ 1 & 1 & 1 & 1 & 1\end{array}-$ desapreço (5)

$\begin{array}{llllll}1 & 2 & 3 & 4 & 5 & 1 \\ 1 & 1 & 1 & 1 & 1\end{array}$

$\begin{array}{lllllll}1 & 2 & 3 & 4 & 5 & - & \text { desprazer (5) }\end{array}$

12 - Segundo você, quais os efeitos da avaliação no avaliado:

- estimulante e motivador ( )

- estimulante ( )

- motivador ( )

- indiferente $($ )

- desmotivadior ( )

- desanimador ( )

- desmotivador e desanimador ( )

- outras formas ( )

13 - Além de avaliar o subordinado, qual a sua participação no processo de availação:

- participa do planejamento e implantação do processo ( )

- participa da elaboraçãa do impresso de avaliação ( .)

- participa das discussões sobre as métodos adotados ( )

- participa das discussões com as subordinados, antes das avaliaç̃os (conteúdo) ( )

- participa das discussóes com os subordinadas, após as avaliaçóes (resultados) ( )

- não tem nenhuma outra participação ( )

- outras formas ( ) 
14 - O S.E. utiliza os resultados da avaliação como subsidios para:

- promoção, admissão e demissão de pessoal ( )

- programas de desenvolvimento de pessoal ( )

- mudanças de procedimentos ( )

- outros ( )

15 - O relacionamento do avaliador com o avaliado após a avaliação:

- melhorou ( )

- continua o mesmo ( )

- piorou ( )

- outras formas ( )

16 - O que significa para você: (descrição dos itens do instrumento de avaliação utilizado).

17 - Qual a importância da avaliaçãa?

\section{ANEXO III}

\section{FORMULARIO 3 - AVAIMADO}

1 - Há quanto tempo exerce a profissåo:

- 1 a 2 anos ( )

-4 a 8 anas ()

- 2 a 4 anos ()

- 8 a 16 anos ()

- mais de 16 anos ( )

2 - Fez outros cursos após a graduação:

- atualização (cursos de curta duração) ( )

- especialização (carga horária minima de $240 \mathrm{~h}$ ) ( )

- po-graduação (mestrado e doutoramento) ( )

3 - Quantas vezes foi avaliado:

$\begin{array}{llll}-1-5() & -41-80(,) \\ -6-10() & -81-160() \\ -11-20() & -161 \text { ou mais () } \\ -21-40() & \end{array}$

4 - No conteúdo programático dos cursos que realizou, como estava inserido o assunto avaliação de desempenho:

- o assunto não foi abordado

- abordagem té́rica ( )

- abordagem prática ( )

- abordagem teorico-prática ( )

- outras formas ( )

5 - No hospital onde vocé trabalha qual a orientação dada ao avaliando sobre o processo de avaliação:

- não recebe orientação especifica ( )

- recebe orientação verbal - sistematizada (obedece programação) ( ) - não sistematizada (esclarecimento do duvidas) ( )

- recebe orientaçåo escrita - sistematizada (manual de avaliação) ( )

- outras ( ) 
6 - Quem faz a orientação dos avaliados:

- a administração do hospital ( )

- a chefe do S.E. ( )

- outros serviços do hospital ( )

- colegas de serviço ( )

- outras ( )

7 - No caso do hospital dar orientação ao avaliado, qual a frequêencia dessa orientação:

- quando o avaliado solicita ( )

- quando a administração considera necessária ( )

- existe programação pré-estabelecida para essa orientação ( )

- outras formas

8 -- Quais as técnicas utilizadas pelo avaliador para a obtenção de dados sobre o avaliado:

- observação sistematizada e contínua ( )

- observação sistematizada e esporádica ( )

- observação não sistematizada e contínua ( )

- observação não sistematizada e esporádica ( )

- entrevistas ( )

- comunicaçâo verbal ( )

- comunicação escrita (relatórios) ( )

- reunizes ( )

- outras formas

9 - Assinale os sentimentos que prevalecem em vocé após a avaliação:

- justiça

- lealdade

- honestidade

(1)

- correção

- confiança (1)

- alegria (1)

$\begin{array}{lllll}1 & 2 & 3 & 4 & 5 \\ 1 & 1 & 1 & 1 & 1\end{array}-$ injustiça (5)

\begin{tabular}{rrrrr}
1 & 2 & 3 & 4 & 5 \\
\hline
\end{tabular}

- deslealdade (5)

- imparcialidade

- integridade

- verdade (1)

- conviç̧ão

- apreşo

- calma (1)

- benefício (1)

- prazer (1)

- outros (1)

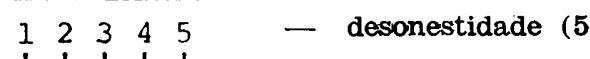

- incorreção (5)

\begin{tabular}{lllll}
1 & 2 & 3 & 4 & 5 \\
\hline
\end{tabular}

- desconfiança (5)

- tristeza (5)

- parcialidade (5)

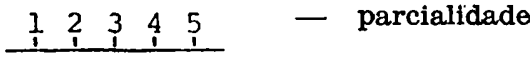

- corrupção (5)

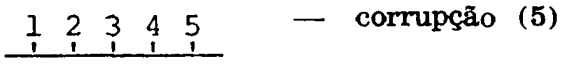

\begin{tabular}{lllll}
1 & 2 & 3 & 4 & 5 \\
1 & 1 & 1 & 1 & 1 \\
\hline 1 & 2 & 3 & 4 & 5
\end{tabular}$-$ inverdade (5)

$\begin{array}{llllll}1 & 1 & 1 & 1 & 1 \\ 1 & 2 & 3 & 4 & 5\end{array}-$ desapreço (5)

$\begin{array}{lllll}1 & 2 & 3 & 4 & 5 \\ 1 & 2 & 3 & 4 & 5\end{array}-$ revolta (5)

\begin{tabular}{llllll}
1 & 1 & 1 & 1 & 1 \\
\hline 1 & 2 & 3 & 4 & 5
\end{tabular}$-$ maleficio (5)

\begin{tabular}{lllll}
1 & 2 & 3 & 4 & 5 \\
1 & 1 & 1 & 1 & 1 \\
\hline 1 & 2 & 3 & 4 & 5
\end{tabular}$-$ desprazer (5) 
10 - Que efeitos a avaliação causa em você:

- estimulante e motivador ( )

- estimulante ( )

- motivador ( )

- indiferente ( )

- desanimador ( )

- desmotivador ( )

- desanimador e desmotivador ( )

- outras formas ( )

11 - Além de ser avaliado qual a sua participação no processo de avaliação:

- participa do planejamento e implantação do processo ( )

- participa da elaboração do impresso de avaliação ( )

- participa das discussóes sobre os métodos adotados ( )

- participa das discussões com as chefes, antes das avaliaçðes (conteúdo) ( )

- participa das discussões com os chefes, após as avaliaç̃es (resultados) ( )

- não tem nenhuma outra participação ( )

- outras formas ( )

12 - O Serviço de Enfermagem utiliza as resultadas da avaliação como subsídios para:

- promoção, admissão e demissão do pessoal ( )

- programas de desenvolvimento de pessoal ( )

- mudanças de procedimentos ( )

- outras ( )

13 - O relacionamento do avaliador com o avaliado aṕ́s a avaliação:

- melhorou ( )

- continua o mesmo ( )

- piorou ( )

- outras formas ( )

14 - O que significa para você: (descrição das itens do instrumento de avaliação utilizado).

15 - Qual a importancia da avaliaçăo? 